\title{
OBTAINING HIGH PURITY SILICA FROM RICE HULLS
}

\author{
José da Silva Júnior e Carlo R. da Cunha* \\ Departamento de Engenharia Elétrica, Universidade Federal de Santa Catarina, 88040-900 Florianópolis - SC, Brasil \\ Flávio L. S. de Carvalho e Ubirajara P. Rodrigues Filho \\ Instituto de Química de São Carlos, Universidade de São Paulo, CP 13560-970 São Carlos - SP, Brasil \\ Paulo R. Oliveira e Marcos A. Segatto Silva \\ Departamento de Farmácia, Universidade Federal de Santa Catarina, 88040-900 Florianópolis - SC, Brasil
}

Recebido em 15/4/09; aceito em 29/10/09; publicado na web em 10/3/10

\begin{abstract}
Many routes for extracting silica from rice hulls are based on direct calcining. These methods, though, often produce silica contaminated with inorganic impurities. This work presents the study of a strategy for obtaining silica from rice hulls with a purity level adequate for applications in electronics. The technique is based on two leaching steps, using respectively aqua regia and Piranha solutions, which extract the organic matrix and inorganic impurities. The material was characterized by Fourier-transform infrared spectroscopy (FTIR), powder x-ray diffraction (XRD), x-ray fluorescence (XRF), scanning electron microscopy (SEM), particle size analysis by laser diffraction (LPSA) and thermal analysis.
\end{abstract}

Keywords: rice hulls; silica; leaching.

\section{INTRODUCTION}

It is well known that silicon dioxide $\left(\mathrm{SiO}_{2}\right)$ is one of the most important materials in the semiconductor industry where it finds applications ranging from gate dielectric in transistors to optical devices. ${ }^{1,2}$ Normally, $\mathrm{SiO}_{2}$ is obtained from mineral sources such as quartzite, but it has been recently found that $\mathrm{SiO}_{2}$ can also be obtained from bionatural resources such as rice hulls. Normal rice hulls are composed of approximately $80 \mathrm{wt}$ \% of organic compounds, where 50 wt. $\%$ consists of cellulose and hemicellulose, 26 wt. $\%$ consists of lignin and the remaining $4 \mathrm{wt}$. $\%$ consists of oils and proteins. The additional $20 \mathrm{wt}$ \% is composed of inorganic compounds, where 18 wt. $\%$ consists of silica. ${ }^{3}$

Thermal treatments of the rice hulls up to $400{ }^{\circ} \mathrm{C}$ under inert atmosphere are typically unable to completely eliminate the lignin, yielding a black char/silica composite. ${ }^{4,5}$ Thus, many options for leaching and extracting silica have been developed. ${ }^{6-8}$ For instance, Proctor and Kamath have developed a method for obtaining silica from rice hull ashes with a strong base treatment. ${ }^{9}$ Conversely, some groups have reported that cleaning the rice hull after a heat treatment step may produce even more inorganic contaminants than beforehand culminating in purity levels as high as $99.66 \% .810$ This article reports an alternative procedure for improving the purity of the silica extracted from rice hulls based on wet chemical pre-treatment of the calcined rice hulls.

\section{EXPERIMENTAL}

Analytical reagent grade hydrochloric acid $(\mathrm{HCl})$, sulfuric acid $\left(\mathrm{H}_{2} \mathrm{SO}_{4}\right)$, nitric acid $\left(\mathrm{HNO}_{3}\right)$ and hydrogen peroxide $\left(\mathrm{H}_{2} \mathrm{O}_{2}\right)$ were used in this study. Hydrochloric acid (40\%) (Nuclear) was purchased from Casa da Química Ind. E Com. Ltda., sulfuric acid (98\%) and hydrogen peroxide $(30 \%)$ were purchased from Cromato Produtos Químicos Ltda., and nitric acid (65\%) (Quimex) was purchased from F. Maia Ind. e Com. Ltda. All chemicals were used as supplied. The rice hulls were obtained from Arroz Soltinho (São José, SC, Brazil) in the southern region of Brazil.

\footnotetext{
*e-mail: creq@eel.ufsc.br
}

In the first step, $30 \mathrm{~g}$ of rice hull were reacted with $400 \mathrm{~mL}$ of freshly prepared aqua-regia $\left(\mathrm{HCl}: \mathrm{HNO}_{3}-3: 1, \mathrm{v}: \mathrm{v}\right)$. The solution underwent constant stirring for one hour and was then vacuum filtered using a sintered glass filter (porosity G1). The filtrate was thoroughly washed with deionized water until no further change in coloration was observed.

For the second step, the cleaned filtrate reacted with $180 \mathrm{~mL}$ of freshly prepared Piranha solution $\left(\mathrm{H}_{2} \mathrm{SO}_{4}: \mathrm{H}_{2} \mathrm{O}_{2}-2: 1\right.$, v:v). The rice hull was treated for 30 min under a constant temperature of $90{ }^{\circ} \mathrm{C}$ and constant stirring. After the reaction, the filtrate was washed with deionized water until no further change in the coloration was observed.

Sulfuric acid, nitric acid and hydrogen peroxide are highly corrosive chemicals and must be manipulated in a fume hood using appropriate personal protection equipment according to their Material Safety Data Sheets (MSDS). The piranha and aqua regia solutions are highly corrosive and can be explosive. They must be prepared inside a fume hood by carefully mixing the chemicals, keeping the recipients for their preparation under refrigeration and allowing sufficient time for the solutions to reach ambient temperature. The use of personal protection equipment such as splash goggles, gloves and laboratory coat is mandatory. All chemical wastes are filtered, collected in appropriate containers (glass or plastic, but preferentially PTFE), diluted and neutralized according to their MSDS (typically baking soda), and discarded by local safety authorities. Used solutions are treated as hazardous waste.

The last step consisted of calcining the remaining filtrate at a constant temperature of $600{ }^{\circ} \mathrm{C}$ for $4 \mathrm{~h}$ in a muffle furnace (Fornitec Model 3394) in an air atmosphere.

\section{Characterization}

The characterization was performed with thermogravimetric analysis (TGA), differential TGA (DrTGA), differential scanning calorimetry (DSC), x-ray fluorescence (XRF), Fourier transform infrared spectroscopy (FTIR), x-ray diffraction (XRD), particle size analysis by laser diffraction (LPSA) and scanning electron microscopy (SEM).

TGA and DrTGA curves were obtained with a Shimadzu TGA50 thermobalance in a temperature range between 30 and $800{ }^{\circ} \mathrm{C}$ using platinum crucibles with approximately $5 \mathrm{mg}$ of the sample under a 
dynamic $\mathrm{N}_{2}$ atmosphere $(50 \mathrm{~mL} / \mathrm{min})$ and a heating rate of $10^{\circ} \mathrm{C} /$ min. The thermobalance was previously calibrated with a calcium oxalate standard.

The DSC curves were obtained using a Shimadzu DSC 60 using aluminum pans with about $2 \mathrm{mg}$ of samples under a dynamic nitrogen atmosphere $(50 \mathrm{~mL} / \mathrm{min})$. The temperature range was between 30 and $500{ }^{\circ} \mathrm{C}$ and the heating rate was $10^{\circ} \mathrm{C} / \mathrm{min}$. An empty aluminum pan was used as reference. The DSC cell was calibrated with a standard reference of indium.

XRF results were obtained with a Shimadzu EDX 700 capable of determining elements from $\mathrm{Na}(Z=11)$ to $U(Z=92)$. The instrument is equipped with an Rh target, the tube voltages were of $50 \mathrm{kV}$ (Ti-U) and $15 \mathrm{kV}(\mathrm{Na}-\mathrm{Sc})$, their operating energies were up to 40 and 4.4 $\mathrm{keV}$ respectively, the aperture was $10 \mathrm{~mm}$ of diameter, the detector was $\mathrm{Si}(\mathrm{Li})$, the measuring time was $100 \mathrm{~s}$ and the atmosphere was air.

The diffractograms were taken with a Philips X'Pert system running with a power supply of $40 \mathrm{kV}, 20 \mathrm{~mA}$ of current, a detection time of $1 \mathrm{~s}$, a step angle of $0.05^{\circ}$ and a $\mathrm{Cu}\left(\mathrm{K}_{\alpha}\right)$ wavelength of $1.5418 \AA$ A. The experimental diffraction patterns were corrected for Lorentz and polarization factors. To determine the cristallinity, the fast Fourier transform of each corrected and filtered diffratogram was taken. The ratio between the power corresponding to high frequency components and the total power gives the cristallinity degree. This procedure was based on the idea that sharp peaks correspond to well organized crystallites whereas broad features correspond to a degree of amorphization.

FTIR spectra were obtained with a Shimadzu Prestige-21. The infrared spectra were collected in transmission mode with a nominal resolution of $4 \mathrm{~cm}^{-1}$ and using the $\mathrm{KBr}$ pellet method.

The granulometry was obtained using a HELOS analyzer by Sympatec. The instrument works with a laser wavelength of 632.8 $\mathrm{nm}$ providing a measurement range from 0.1 to $8750 \mu \mathrm{m}$.

All microscopy images were obtained using the secondary electron detector of a JEOL SEM model JSM-6390LV. All samples were coated with $35 \mathrm{~nm}$ of gold prior the imaging using a SPI Sputter Coater model 11430. All images were taken with an accelerating voltage of $15 \mathrm{kV}$.

\section{RESULTS AND DISCUSSION}

The rice hull is composed of $8,86 \mathrm{wt}$. \% of sorbed water, 78,01 wt. $\%$ of organic matter and 13,13 wt. \% of inorganic matter measured with a maximum tolerance of $1,76 \%$. The inorganic components are listed in Table 1. The major component are $\mathrm{Si}$ and $\mathrm{O}$, however there are minor components such as $\mathrm{P}, \mathrm{Ca}, \mathrm{Mn}$ and $\mathrm{Fe}$ probably clustered together forming phytate salts. ${ }^{11,12}$ The sulfur found is probably related to impurities or lipoproteins sorbed in the lignocellulosic composite.

Table 1. Results from the x-ray fluorescence in [wt. \%] after each processing step. The water and organic contents were discounted

\begin{tabular}{lcccc}
\hline & $\begin{array}{c}\text { Raw } \\
\text { Material }\end{array}$ & $\begin{array}{c}\text { Aqua } \\
\text { Regia Leaching }\end{array}$ & $\begin{array}{c}\text { Piranha } \\
\text { Leaching }\end{array}$ & $\begin{array}{c}\text { Heat } \\
\text { Treatment }\end{array}$ \\
\hline $\mathrm{O}$ & 52.08 & 32.21 & 40.74 & 53.26 \\
$\mathrm{Si}$ & 42.73 & 27.59 & 34.02 & 46.74 \\
$\mathrm{P}$ & 1.22 & 0 & 0 & 0 \\
$\mathrm{~S}$ & 0.43 & 0.40 & 1.27 & 0 \\
$\mathrm{Cl}$ & 0 & 39.36 & 23.78 & 0 \\
$\mathrm{~K}$ & 1.24 & 0 & 0 & 0 \\
$\mathrm{Ca}$ & 1.25 & 0.33 & 0 & 0 \\
$\mathrm{Cr}$ & 0.09 & 0.11 & 0 & 0 \\
$\mathrm{Mn}$ & 0.18 & 0 & 0 & 0 \\
$\mathrm{Fe}$ & 0.77 & 0 & 0.18 & 0 \\
\hline
\end{tabular}

The main organic compounds present in the raw materials can be qualitatively assessed by FTIR (Figure 3). The features at 1089 can be assigned to the $v_{\text {ass }}(\mathrm{C}-\mathrm{O}-\mathrm{C})$ group of the polysacharides and $v_{\text {ass }}\left(\mathrm{Si}-\mathrm{O}-\mathrm{Si}\right.$ ) in the silica rings having 4 and 6 members, ${ }^{13}$ while the band at $1330 \mathrm{~cm}^{-1}$ is assigned to the syringil group of the lignin. The absence of remarkable bands between $1260-1270 \mathrm{~cm}^{-1}$ indicates a low amount of guaycil groups. ${ }^{13}$ The band at $1206 \mathrm{~cm}^{-1}$ is also related to the aromatic C-O lignin functional groups. The bands in 1660 and $1728 \mathrm{~cm}^{-1}$ are related to the lignin carbonyl groups, wherein the less energetic vibrational transition is assigned to $\mathrm{C}=\mathrm{O}$ that is in conjugation with aromatic rings, and the more energetic ones are assigned to unconjugated $\mathrm{C}=\mathrm{O}$. The band at $1604 \mathrm{~cm}^{-1}$ and the very broad band at $3386 \mathrm{~cm}^{-1}$ correspond to sorbed water and-OH groups in cellulose and lignin. The 2850 and $2916 \mathrm{~cm}^{-1}$ bands are assigned to the asymmetric and symmetric $\mathrm{CH}_{2}$ groups in the lignin and cellulose. These bands can be used as markers for the total organic matter in the treated hulls.

The two weight losses between 310 and $400{ }^{\circ} \mathrm{C}$ in the DrTGA of the rice hull in Figure 1 correspond to exothermic events with significant loss of mass ( $35 \mathrm{wt}$. \%) assigned to the pyrolysis of the cellulose and hemicellulose in agreement with the results previously reported by Teng and Wei. ${ }^{14}$ The more pronounced peak in the DrTGA curve of the untreated rice hull indicates the leaching of organic matter as in several essayed treatments. The second event at $470^{\circ} \mathrm{C}$ corresponds to an exothermic event which does not involve a significant loss of mass. This event is probably due to the degradation of lignin resulting on char/silica composites. ${ }^{4,5,15}$ The XRD shown in Figure 2 supports these ideas indicating a crystallinity degree of approximately $27 \%$ for the raw material related to lignin and $\alpha$-cellulose in agreement with Rodrigues Filho. ${ }^{16}$

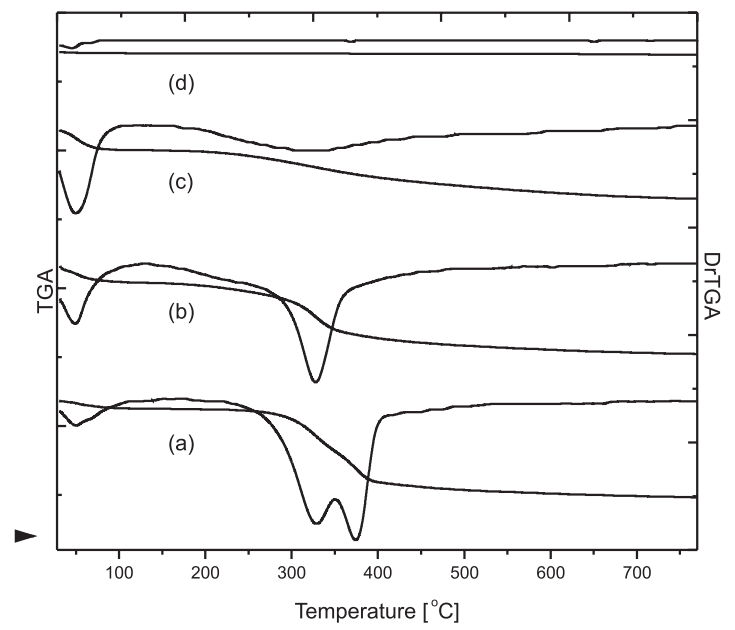

Figure 1. Normalized TGA and DrTGA plots for a) the raw material, b) the material after aqua-regia leaching, c) the material after Piranha leaching, and d) the material after heat treatment

The aqua-regia treatment eliminates the peak at $359^{\circ} \mathrm{C}$ from the DrTGA curve, indicating the loss of hemicellullose from the raw material. This can be understood by the fact that hemicellulose is more accessible to acid hydrolysis than cellulose because of its amorphous nature. ${ }^{17}$ The carboxylic acid component at $1729 \mathrm{~cm}^{-1}$ in the infrared spectra of Figure 3 also increases in intensity. The aqua-regia treatment eliminates phytate efficiently, which could be separated to be used as a metal sequestering agent. The DrTGA of the material after the aquaregia treatment shows only one pronounced peak between 310 and $400{ }^{\circ} \mathrm{C}$ corresponding to cellulose. This indicates the extraction of the lignin as a nitrated product, as also inferred by the deep orange color of the formed liquor. Once neutralized and filtered, these deep orange compounds could possibly be used as fabric pigments to improve the 


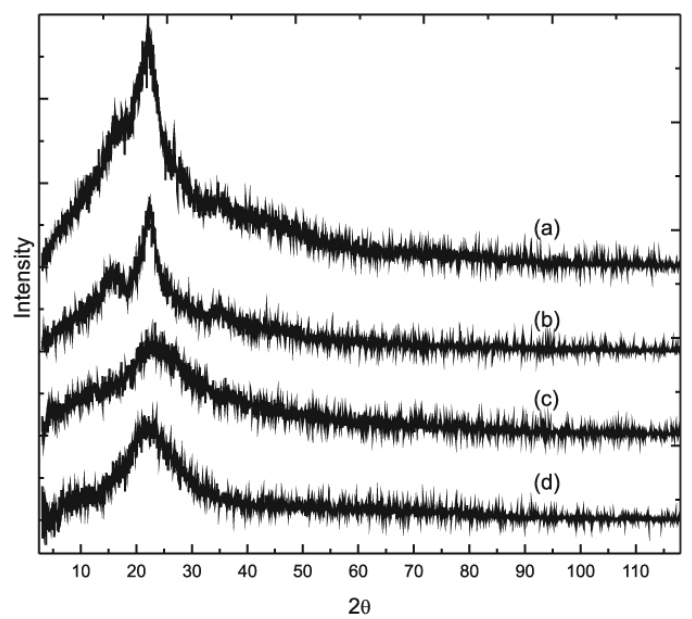

Figure 2. Corrected XRD profiles for a) the raw material, b) the material after aqua-regia leaching, c) the material after Piranha leaching, and d) the material after heat treatment

sustainability of the chemical process. Chloride appears in the XRF analysis because of hydrochloric acid sorbed by the material. The infrared spectrum of the aqua-regia treated sample displays an increase in the water bands, a broadening of the bands between 1200 and 1450 $\mathrm{cm}^{-1}$, and a decrease in the relative intensity of the $1664 \mathrm{~cm}^{-1}$ band, probably related to partial removal of lignin aromatic groups from the hulls and partial oxidation/nitration of the remaining organic matter. ${ }^{18,19}$ Moreover, the cristallinity degree extracted from the corresponding XRD diffratogram (Figure 2) is about the same as in the raw rice hull, indicating that the material did not suffer any significant structural change. According to the XRF results, aqua-regia is also responsible for a significant etching of inorganic elements with low solubilization that do not appear in the x-ray fluorescence spectra (not showed). The aqua-regia treatment alone is unable to remove all organic matter.

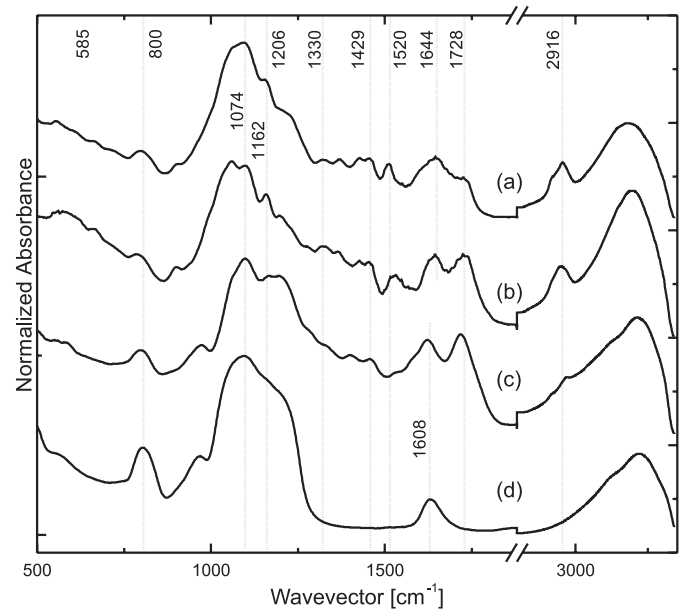

Figure 3. Normalized infrared spectra for a) the raw material, b) the material after aqua-regia leaching, c) the material after Piranha leaching, and d) the material after heat treatment

All samples showed losses below $100{ }^{\circ} \mathrm{C}$ in their thermal stability data of Figure 1indicating water adsorption. However, it is possible to observe a higher loss $(\sim 8.6$ wt. \%) after the Piranha treatment as compared to the raw material $(\sim 2.4$ wt. \%), in agreement with previously reported acid treatments. ${ }^{4}$ This can be attributed to an increase of surface area and hidrophilicity caused by the attack of such strong oxidant solution. The increase in surface area is also supported by amorphization of the material by oxidation of the lignocellulosic ma- trix given that the crystallinity degree inferred from the corresponding x-ray diffratogram (Figure 2) was reduced to approximately $23 \%$.

The TGA obtained after the Piranha treatment (Figure 1) shows that the peaks corresponding to the loss of mass related to the pyrolisis of cellulose and hemicellulose have almost completely disappeared. On the other hand, the DSC curve (Figure 4) still shows two features at temperatures previously associated with cellulose, hemicellulose and lignin. These features may correspond to some remaining organic matter that is chemically and mechanically bound to silica nanoparticles. For instance, similar recalcitrant organic matter has been observed after vigorous oxidizing treatment of soils. ${ }^{15,19}$ FTIR data in Figure 3 shows, indeed, a reduction of organic matter covering the inorganic part as indicated by the bands at 2850 and $2916 \mathrm{~cm}^{-1}$. Sulfur, which is present in the XRF data, is probably introduced by the sulfuric acid present in the Piranha solution.

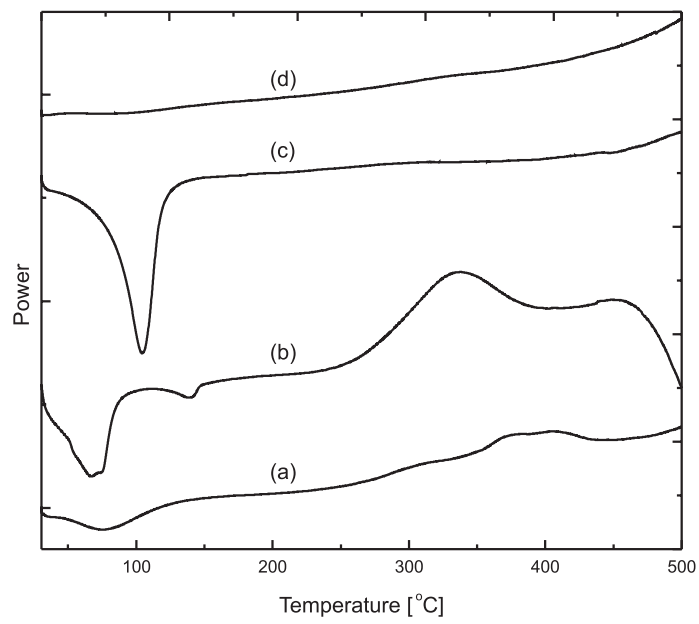

Figure 4. Normalized DSC data for a) the raw material, b) the material after aqua-regia leaching, $c$ ) the material after Piranha leaching, and d) the material after heat treatment

The oxidizing Piranha solution eliminates the organic matter adsorbed on the surface, thus exposing the silica surface which is indeed non-crystalline.

The TGA plot corresponding to the heat treated sample (Figure 1) does not show clear thermal events other than the water loss. It is important to note a sharp decrease in water loss percentage after the thermal treatment indicating a decrease of surface area and change in surface chemical composition probably related to loss of residual organics. FTIR (Figure 3) also shows a complete removal of organic matter by the absence of peaks between 2800 and $2900 \mathrm{~cm}^{-1}$ corresponding to $\mathrm{CH}_{2}$ and $\mathrm{CH}_{3}$ groups as well as the ligninocellulosic characteristic peaks. On the other hand, the peak corresponding to $\mathrm{Si}-\mathrm{O}-\mathrm{Si}$ is very clear at $1107 \mathrm{~cm}^{-1}$. XRF does not show metals, sulfur or phosphorous but silicon and oxygen. Therefore, both spectroscopies suggest the presence of silicon dioxide with a purity higher than that obtained with standard treatments. ${ }^{8,10}$ This is highly desirable by the electronics industry, since contaminants such as $\mathrm{Na}$ and $\mathrm{K}$ are usually mobile in the oxide and cause degradations in the insulating properties of silica. Moreover, the x-ray diffratogram (Figure 2) shows a cristallinity degree of $28 \%$. This treatment also has the benefit of working as a post-oxidation anneal, which is known to lower the density of traps. ${ }^{20}$

According to the LPSA data (Figure 5), the final product is composed entirely by particles smaller than $100 \mu \mathrm{m}$. Furthermore, the data indicates an average particle size of approximately $50 \mu \mathrm{m}$. SEM images of the distribution of particles on scales of 500 and 50 $\mu \mathrm{m}$ are shown in Figures 6 and 7, respectively. 


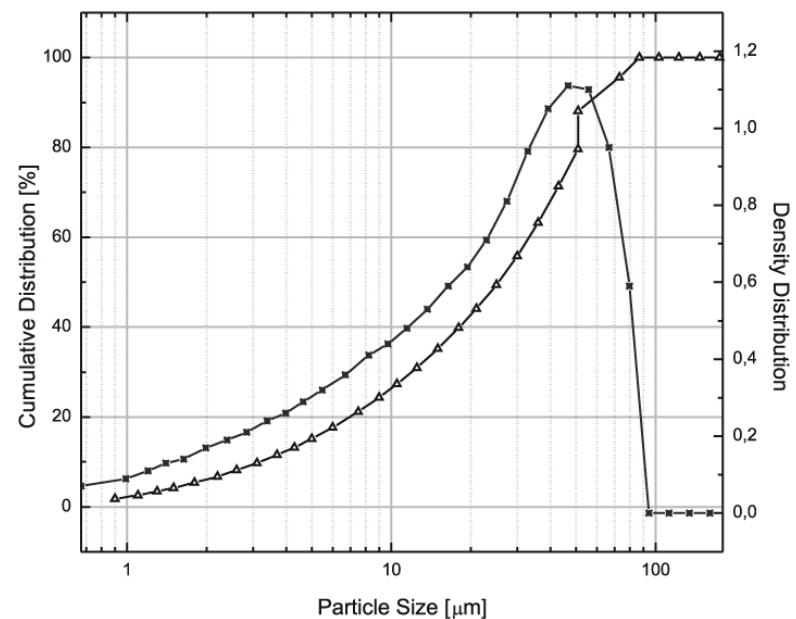

Figure 5. Cumulative distribution and density distribution of particle sizes obtained by LPSA for the final material

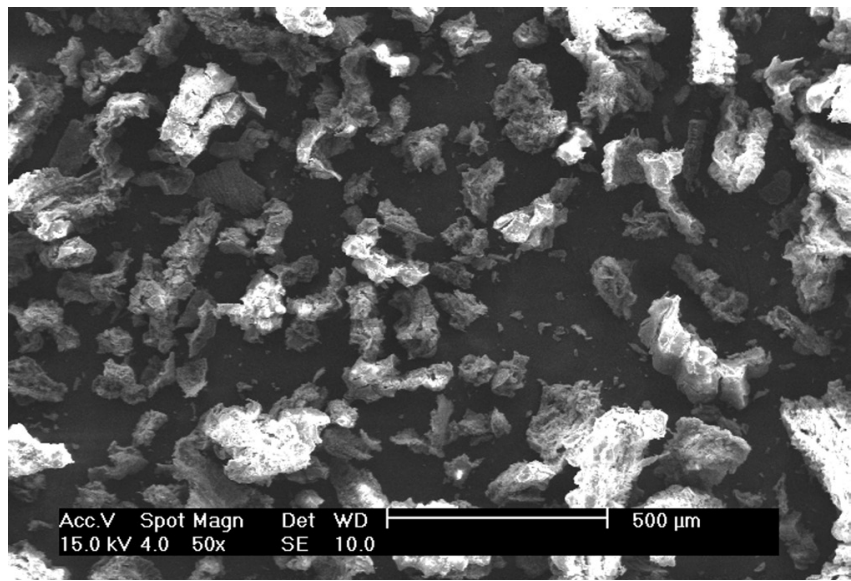

Figure 6. SEM image of the distribution of particles from the final material on a scale of $500 \mu \mathrm{m}$

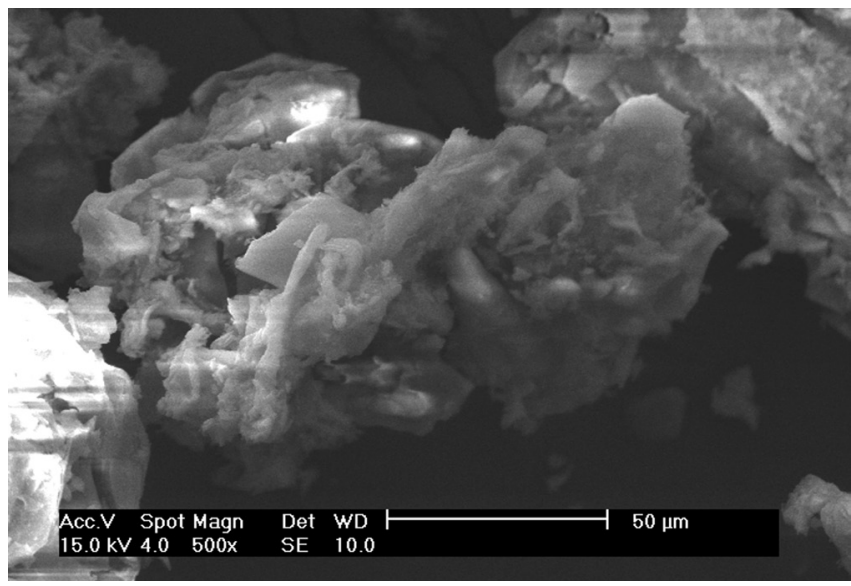

Figure 7. SEM image of the final material on a scale of $50 \mu \mathrm{m}$

\section{CONCLUSIONS}

We have shown the study of an alternative route for obtaining electrical grade silica from rice hulls. Results suggest that aqua-regia strongly removes inorganic elements as well as solubilize aromatic rings from lignin. The piranha treatment is responsible for a removal of the remaining organic matter. Both acid treatments are responsible for a significant decrease in the number of inorganic contaminants, and the heat treatment eliminates recalcitrant organic matter. Although the proposed route to obtain silica may be considered pollutant due to the use of highly corrosive chemicals, it produces silica adequate for the electronics industry. Nonetheless, an integrated analysis of the protocol could be regarded as more environmental friendly if the wastes could be transformed into byproducts as suggested in the text. For instance, the $\mathrm{CO}_{2}$ produced by the heat treatment has a high level of purity and could be used for supercritical drying to produce aerogels, an ongoing project in our laboratories. Furthermore, the solution obtained after the aqua regia treatment reveals a deeply orange colorant that could be used by the textile industries. The total consumption of chemicals necessary to produce one gram of silica using this route is $0,75 \mathrm{~mL}$ of nitric acid, $2,25 \mathrm{~mL}$ of hydrochloric acid, 1,2 mL of sulfuric acid and $0,6 \mathrm{~mL}$ of hydrogen peroxide. Ignoring gains of scale production, this route is able to produce silica with an appropriate purity level for the electronics industry with an equivalent cost of approximately $11 \mathrm{~kg}$ of gold per ton of silica. If the byproducts are also used then this route becomes particularly interesting, given that the same amount of silica can be purchased by twice as much today.

\section{REFERENCES}

1. Teng, J. H.; Dong, J. R.; Chua, S. J.; Foo, B. S.; Lai, M. Y.; Wang, Y. J.; Ang, S. S.; Yin, R.; Appl. Phys. Lett. 2007, 90, 171107.

2. Ruske, M.; Bräuer, G.; Pistner, J.; Szczyrbowski, J.; Weigert, M.; Thin Solid Films 1999, 351, 158.

3. de Souza, M. F.; Magalhães, W. L. E.; Persegil, M. C.; Mater. Res. 2002, $5,467$.

4. Siqueira, E. J.; Yoshida, I. V. P.; Pardini, L. C.; Schiavon, M. A.; Ceram. Int. 2009, 35, 213

5. Markovska, I. G.; Lyubchev, L. A.; J. Therm. Anal. Calorim. 2007, 89, 809.

6. Kalapathy, U.; Proctor, A.; Shultz, J.; Bioresour. Technol. 2000, 73, 257.

7. Kalapathy, U.; Proctor, A.; Shultz, J.; Bioresour. Technol. 2002, 85, 285.

8. Yalcin, N.; Sevinc, V.; Ceram. Int. 2001, 27, 219.

9. Kamath, S.; Proctor, A.; Cereal Chem. 1998, 75, 484.

10. Della, V. P.; Hotza, D.; Junkes, J. A.; de Oliveira, P. N.; Quim. Nova 2006, 29, 1175.

11. Filho, U. P. R.; Vaz Jr., S.; Felicissimo, M. P.; Scarpellini, M.; Cardoso, D. R.; Vinhas, R. C. J.; Landers, R.; Schneider, J. F.; McGarvey, B. R.; Andersen, M. L.; Skibsted, L. H.; J. Inorg. Biochem. 2005, 99, 1973.

12. Crea, F.; De Stefano, C.; Milea, D.; Sammartano, S.; Coord. Chem. Rev. 2008, 252, 1108.

13. Liu, Q.; Wang, S.; Zheng, Y.; Luo, Z.; Cen, K.; J. Anal. Appl. Pyrolysis 2008, 82,170 .

14. Teng, H.; Wei, Y. C.; Ind. Eng. Chem. Res. 1998, 37, 3806

15. Bharadwaj, A.; Wang, Y.; Sridhar, S.; Arunachalam, V. S.; Curr. Sci. 2004, 87,981

16. Filho, U. P. R.; Gushikem, Y.; Fujiwara, F. Y.; Langmuir 1994, 10, 4357.

17. Zhu, Z.; Sathitsuksanoh, N.; Vinzant, T.; Schell, D. J.; McMillan, J. D.; Zhang, Y.-H. P.; Biotechnol. Bioeng. 2009, 103, 715.

18. Khvan, A. M.; Abduazimov, B. B.; Abduazimov, K. A.; Chem. Nat. Compd. 2002, 38, 471.

19. Lombardi, K. C.; Mangrich, A. S.; Wypych, F.; Filho, U. P. R.; Guimarães, J. L.; Schreiner, W. J.; J. Colloid Interface Sci. 2006, 295 , 135.

20. Hori, T.; Gate Dielectrics and MOS ULSIs, Springer-Verlag: Heidelberg, 1997. 